\title{
Promises to keep
}

\author{
ANDREW DOUGLAS \\ Presidential address delivered to the British Thoracic Society on 8 December 1983
}

The woods are lovely, dark and deep, But I have promises to keep And miles to go before I sleep. ROBERT FROST

When the council of the British Thoracic Society decided earlier this year that there should be a presidential address there was no lack of well meaning advice on the form this should take, although in retrospect most of it turned out to be of negative value. One member said, "We don't want a travelogue"; another, "We don't just want a favourite lecture"; and yet another said, "There will be plenty of science on the programme already." One very kindly colleague said, "Just talk about anything you like, even railways." Sadly, I know very little about railways so I found it somewhat difficult to find a topic which would avoid these constraints and still be relevant to our young society. It was while trying to resolve this dilemma that I happened to look at a picture which came into our possession some 40 years ago (fig 1 ). It is painted on wood by an unknown artist and for almost a century it had been set in the wall above the dispensing desk of a well known Edinburgh pharmaceutical firm. It shows the casual encounter on a country road between a doctor and a patient, both on horseback. It is called "The Diagnosis," and probably the scene was set around the turn of the eighteenth century. The picture set off a train of thought. What, I wondered, was the doctor's background? What were his obligations to his patient, to his profession and to society as a whole? And how well do we do his job today?

It is reasonable to believe that the picture relates to a Scottish scene but even if it does not the chances are high that the doctor graduated from a Scottish university, for most of the medical training in the British Isles at that time took place in Scotland. For example, in the years $1800-50$ there were nearly 8000 graduates from the four Scottish medical schools compared with less than $\mathbf{3 0 0}$ from Oxford and Cambridge, the only other universities then awarding medical degrees. Possibly he was an Edin-

Address for reprint requests: Dr Andrew Douglas, Department of Medicine, Royal Infirmary, Edinburgh EH3 9YW.

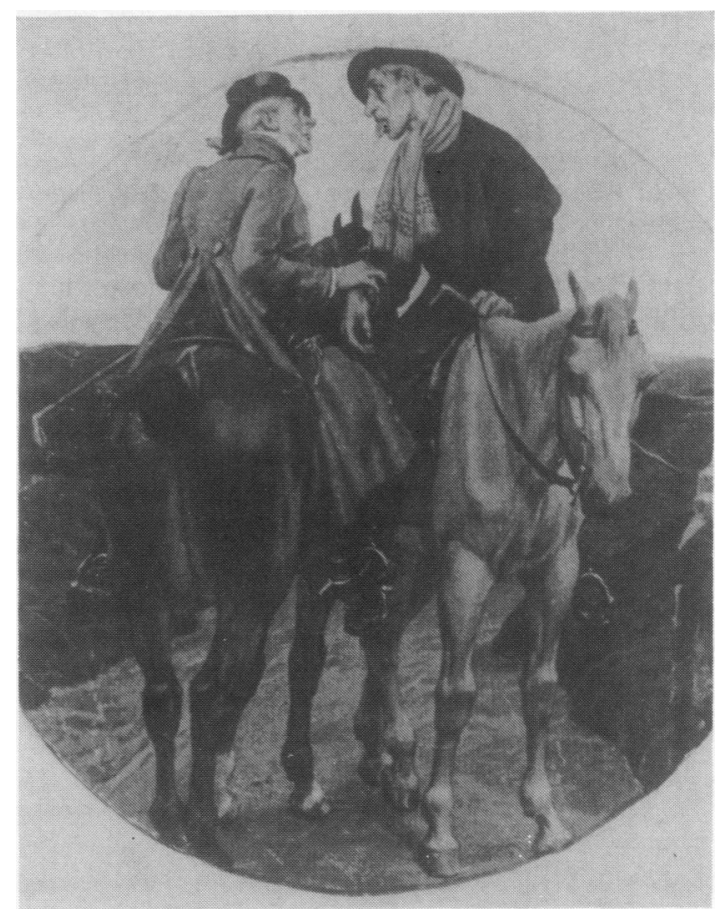

Fig 1 The diagnosis.

burgh graduate who studied under Joseph Black; conceivably he was William Dean, whose certificate of attendance at Black's chemistry class, signed by Black himself, is shown in fig 2. Perhaps he took part in one of Black's lesser known experiments, which meant laying rugs soaked in caustic soda in the roof of a church. At the end of a long service Black proved that the caustic soda had become a mild alkali and was eventually satisfied that air was not an element but a mixture of different gases.

The likelihood is that the doctor was at least of middle class origin, perhaps a son of the manse or a doctor's son. The "lad o' pairts," the beneficiary of the arrangement whereby a poor Scottish community would collectively support the university training of an outstanding scholar, was more likely at that time to opt for a career in teaching or the church than for medicine. The requirements for admission 


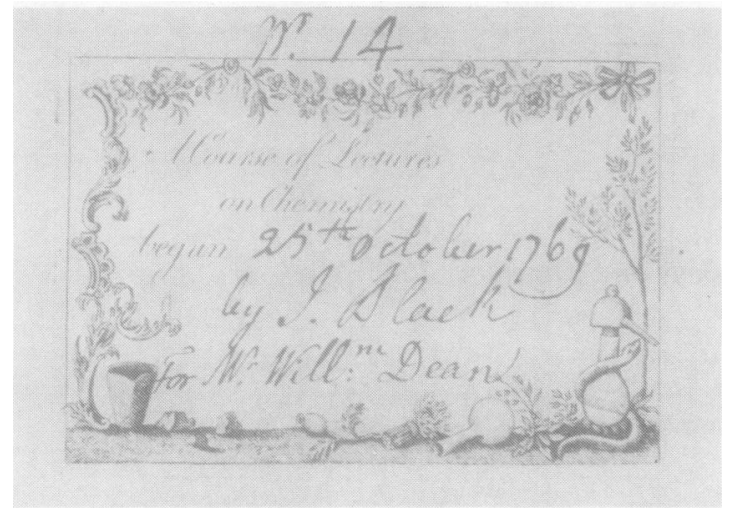

Fig 2 William Dean's chemistry class certificate signed by Joseph Black.

to university were vastly different from those today. William Dean could have matriculated as early as 15 and, although some indication of a sufficient standard of school education would be demanded, usually this meant only the school teacher's recommendation and there was little competition for entry.

The contrast with today is striking and the high standards demanded by medical schools in Britain

Table 1 Admissions to the Faculty of Medicine, University of Edinburgh, 1982*

\begin{tabular}{lcc}
\hline & Men & Women \\
\hline Number of applicants & 863 & 669 \\
Number accepted & 166 & 149 \\
Percentage accepted & 19 & 22 \\
Number enrolled & 100 & 91 \\
Percentage enrolled & 12 & 14
\end{tabular}

Entrance qualifications of those enrolled

Scottish Certificate of Education (50\%)

General Certificate of Education (50\%)
Majority

Minimum

Majority Minimum
AAAAA plus AAABB

AAA plus ABB

*Reproduced by courtesy of the Executive Dean, Faculty of Medicine, University of Edinburgh.

are highlighted by some recent figures for Edinburgh, which reflect fairly well the standards throughout the country (table 1). It would seem that medicine now creams off the top layer of academic potential and there is no evidence that this is a passing phenomenon (fig 3). As we stand on the brink of Orwell's fabled year, with all its other connotations, the barometer of twenty-first century

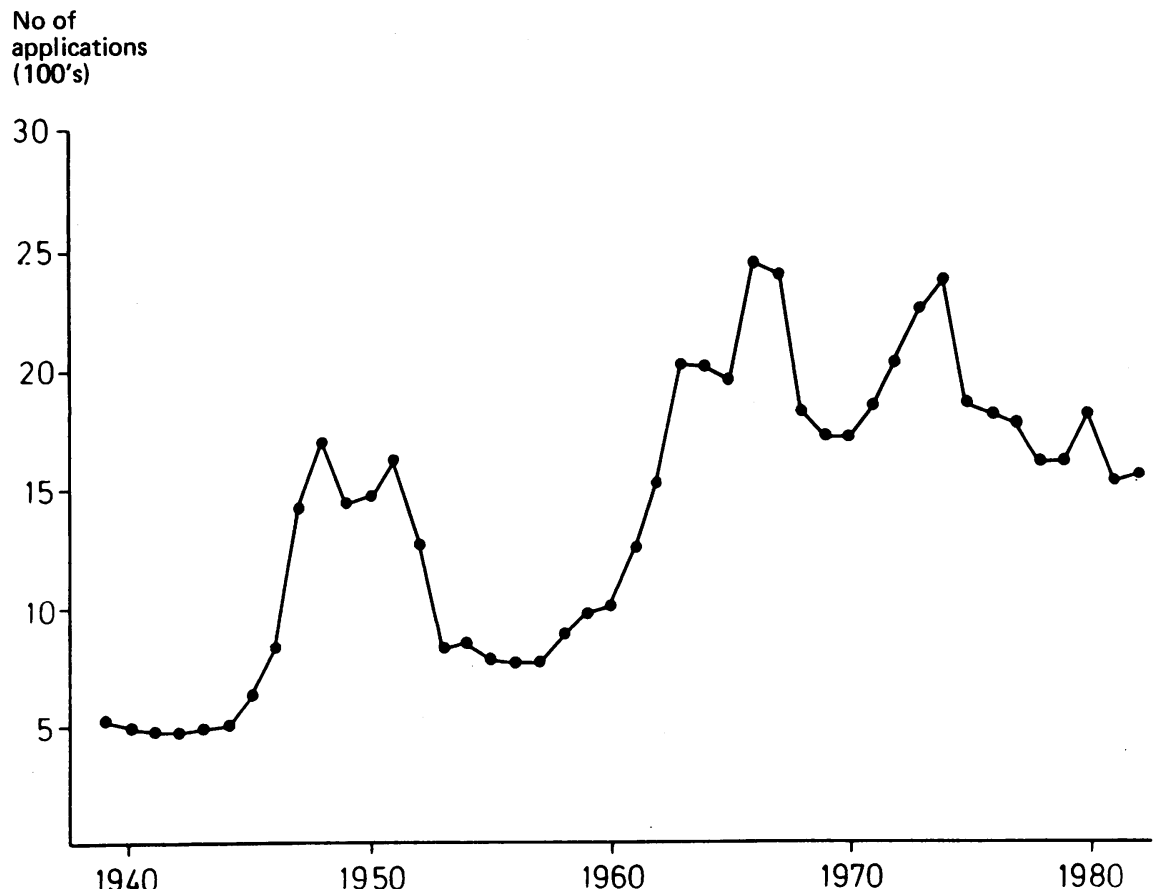

Fig 3 Applications for entry to the Edinburgh medical school, 1940-80. Reproduced by courtesy of the Executive Dean, Faculty of Medicine, University of Edinburgh. 
medicine seems set fair. But here we come across a first obligation or promise. We must make the best use of this potential and as a thoracic society with a high proportion of its members heavily committed to medical training we have a duty to make that training match the capabilities of this extraordinarily gifted segment of society.

Whether or not academic excellence at school is the best index for selection of medical students remains debatable. But at least it is a quantifiable phenomenon and in a study of success in the final examinations in the Edinburgh medical school some years ago it was the single most important indicator of the likelihood of completing the course successfully. This does not necessarily mean that this criterion ensures the best end product-given that we can define what that is. It simply means an ability to cope with a defined curriculum and the attainment of a certain standard of knowledge at a point in time. In medicine more than in any other profession, however, today's authority is often tomorrow's folly and the commitment to continue to learn is an essential in the medical life. This was underlined by a study published in June this year of the undergraduate examination performance and subsequent career success of the 1950-1 intake of Cambridge medical students. It was concluded that undergraduate results were poor predictors of later performance. ${ }^{\prime}$ What seems to determine quality in the long run is the motivation to continue to learn, something which medical educators can inculcate only by example.

The relevance of the medical curriculum to today's needs as well as the methods of teaching continues to be under active review. Traditionalists who have experienced radical medical courses such as that of McMaster University have usually regarded these as being several steps up the evolutionary scale from the courses of the traditional university, but even their most fervent supporters are forced to admit that there is basically nothing to choose between the end products. ${ }^{2}$ The reason, it would appear, is that the "hidden curriculum" is a much more powerful learning force than is the written curriculum. The hidden curriculum largely reflects the attitudes and motivations of the teachers, with the result that medical education tends to produce doctors in the image of their teachers. Those of our members who influence and contribute to medical education have a prime obligation to make that hidden curriculum worthy of the place it holds in the shaping of tomorrow's doctors-another promise.

But to return to our horseback physician: it would be wrong to believe that he lived in an unchanging, unchallenging medical world. It is true that the transforming influences of Pasteur, Koch, Lister, and Virchow were still to come but medicine in the early 1800 s was certainly not static. In his medical training he would have learnt about the best piece of physiological work of the eighteenth centurynamely, the completion of the modern theory of respiration, which stemmed from the discovery of the different gases in the atmosphere by Black, Cavendish, Priestley, Rutherford, and Lavoisier (table 2). These discoveries were to lead to the ultimate consummation of the work of the man who revolutionised medical science and who has exerted a more powerful influence on modern medicine than any other. ${ }^{3} \mathrm{He}$ was, of course, William Harvey, another horseback physician, who allowed his servant to follow him on foot, a fashion which his biographer John Aubrey thought "very decent." 4

Our physician would certainly have heard of Harvey's injunctions to colleagues and successors. These were: (1) to advance natural knowledge by way of experiment; (2) to live in amity and friendship together; and (3) to appreciate the acts of our benefactors, and through them to provide for the further development of our service to society. These injunctions are still relevant to members of every learned medical society and they amount to obligations or promises. It was the reality of the second injunction in respiratory medicine today which allowed the British Thoracic Society to be born. In relation to the first injunction, it is highly significant that in the articles of association of our society the words "research" and "study" occur six times and four times respectively on the first page. You and I have subscribed to these articles.

Our multidisciplinary thoracic society exists for the advancement and communication of knowledge and in regard to the various roles we can assume it is perhaps pertinent to remind ourselves that there are essentially only two kinds of scientific activityfirstly, investigations aimed at understanding naturally occurring phenomena-in other words, research-and, secondly, investigations aimed at applying knowledge so gained to human needsthat is, development. ${ }^{5}$ The first is determined by nature, the second by human wishes and intention. Research is essentially a voyage of discovery which cannot be accurately charted in advance and only in the broadest terms can the aim of any individual project be formulated. All that organisation can do

Table 2 Steps in the theory of respiration

\begin{tabular}{lll}
\hline Joseph Black & 1757 & Carbon dioxide \\
Henry Cavendish & 1766 & Hydrogen \\
Joseph Priestley & 1771 & Oxygen \\
Daniel Rutherford & 1772 & Nitrogen \\
Antoine Lavoisier & 1775 & Gas interchange in lungs \\
\hline
\end{tabular}


is to choose the right person as leader, equip him as well as possible with coworkers and materials, and trust to his judgement. By contrast development is more amenable to wishes and intentions. Development starts with a modicum of knowledge that is certain and accepted. It is therefore possible to chart the general course of development, to estimate the resources required, and to follow its progress fairly accurately. So the outcome should be predictable within reasonable limits. Between these two extremes of research and development lie every shade and combination of activity. After the rare pioneers comes the vast army of colonisers. Then come those concerned with the generalities of application and after them those who combine experience of both science and practical activities, whose task it is to develop scientific knowledge for specialised purposes. Over this range of research and development there is no break, either intellectual or practical. Knowledge must flow in both directions, from practice to research just as freely as from research to practice. The context of that knowledge can stretch from the most abstruse to the most practical considerations. It follows, then, that the position of any individual worker in the range of scientific inquiry is not a fixed one. According to the trend of his work and his capabilities he will at different times move more or less towards the theoretical and towards the practical. It is on this natural ebb and flow around an investigator's primary interest that the integration of scientific knowledge rests. ${ }^{5}$

The researcher cannot be indifferent to the use to which his work is put, nor can he be without interest in its implication for the wider body of knowledge. At all times he is bound to be concerned with interests which touch on his own. And so it becomes possible to have concerted action over wide ranges of scientific inquiry. It is salutary to remember that the theory of respiration arose primarily out of the work of mathematicians, physicists, and chemists. Nearer our own day the development of the controlled therapeutic trial, devised by Fisher and Bradford Hill, neither of them physicians, demonstrated the great importance of outside influences and perhaps also the weakness of closed intellectual societies. ${ }^{6}$ The British Thoracic Society, with its basic mechanisms and clinical epidemiology groups and its broadly represented clinical interests, is ideally constituted to promote widely ranging inquiry and multidisciplinary scientific activity-indeed we have promised to do so.

Research is broadly of two kinds, observational and experimental. Until recently research was accorded such prestige that it was in some danger of being elevated into a mystique. This was particularly true of the experimental method, so that in conse- quence the observational approach declined in attraction. But although the experimental method is the single most important tool that man has devised for extending knowledge it has the inherent weakness that it depends for its inception on the formulation of an idea, and consequently can be no stronger than the imagination of the person who uses it. ${ }^{5}$ Observational research, however, relies on the careful collection of data and the interpretation of them. It maps out the association of events and it can generate hypotheses regarding cause. Observation is our main contact with natural reality; it is also our most frequent source of the unexpected in scientific discovery. Darwin's whole work was based on the observational method. Edward Jenner, also a country horseback physician, made observations which were to be the foundation of immunology and ultimately were to rid the world of its most infectious disease. The observations of Parry and Addison were the beginnings of endocrinology, and it was the alert observation of Fleming which led to the discovery of antibiotics. With the great elaboration of technical methods for extending the range of our senses the observational method has become of increasing importance. We should therefore devote considerable attention to its promotion, but having said that we immediately come up against an intrinsic difficulty. Observation, being dependent on the occurrence of natural events, is of necessity a more lengthy process than experiment, which can provoke events at will. It does therefore raise problems of maintaining consistent standards of observation over long periods, of sustaining attention and coordinating efforts, and also of obtaining the necessary long term funding. Our inaugural president clearly indicated the vital need to review the sources of funding available for clinical research. This is especially pertinent in the current climate of relative unwillingness of grant bodies to underwrite this form of scientific activity. Now, as in Harvey's day, the advancement of knowledge depends for its material support on the interest of benefactors. Today our major benefactor is society itself, and only to the extent that we can convince its members of the importance to them of our work will the necessary support be forthcoming. It is our bounden duty to do so.

In Harvey's day, and indeed at the time our horseback physician lived, researchers operated as individuals and the range of medical and biological knowledge could be spanned by a single mind. It was possible then for the researcher to effect the necessary synthesis of knowledge in his own person. Not so today. Medical knowledge is now seemingly infinite and since life is a single experience any individual can be familiar only with a fragment of that 
knowledge, far less be expert in its practical expressions. By the same token it follows that there is room in medicine for talents of every kind. The tremendous broadfronted advance in scientific knowledge after the second world war has never been equalled at any time in man's history, and medicine has consequently been influenced and directed by this new knowledge into channels previously undreamed of. Man is always at the mercy of his own ingenuity and new knowledge always clamours to be used. It would be unthinkable, say, to have discovered the internal combustion engine and not to have used it. A modern example is the computer, which increasingly is influencing medical practice. As a measure of the rate of scientific progress, it is estimated that $98 \%$ of all contributors to mankind's scientific knowledge are still alive today: and it is an awe inspiring thought that only some 60 years after man falteringly flew a few yards in a heavier than air machine he was walking on the moon. The future of medicine will largely be determined by how we can direct and control the products of the present scientific revolution. It is proper that society should demand from us a promise to do this responsibly.

Let me now turn to another aspect of medical practice where promises are pertinent. As Sir Christopher Booth has remarked, it seems fashionable to consider that modern medicine has grown out of touch with the human condition, that so called high technology medicine is somehow inhuman, and that a new breed of doctors, arrogantly scientific, has replaced the beloved physician of a bygone age.? $\mathrm{Sir}$ Christopher could not share such views; nor can we. Almost everything we do to help our patients, whether by effective prevention or by treatment, is based on scientific or technological achievement. It is true that there remain many areas where medical science has yet to cast light and where care and compassion of themselves are more important. But many would feel that there is as much humanity in replacing a damaged aortic valve with the high technology of cardiopulmonary bypass as in caring for someone with an irrecoverable hemiplegia or a chronic mental illness. Of course, not all medicine is "high technology." There are, and always will be, areas of the unknown which will continue to confound the greatest expert. For example, the scientific basis of many disorders of the mind or the personality remains obscure and in this area "fringe medicine" flourishes. Yet it is well to remember how much we owe to fringe medicine. Vaccination and digitalis had their origins in the beliefs and practices of country folk. Ophthalmology was originally developed by unqualified practitioners. Orthopaedics owes much to the old bone setters. Even acupuncture, initially derided by the medical establ- ishment, seems likely to achieve some scientific respectability. ${ }^{7}$ Who would doubt that the spirituality which permeated the work of the late $\mathrm{Dr}$ Winifred Rushforth had an integral part in the care she was able to give to troubled minds and bodies? A similar spirituality is threaded through Dame Cicely Saunders's work today. Advances in treatment certainly may come in unconventional ways but, as with any other therapy, their worth can be established finally only by scientific analysis. Where such analysis has not been carried out in the past the medical profession itself has been responsible for the perpetration of therapeutic horrors just as bad, if not worse, than the excesses of chiropractors and quacks.' Blood letting was a prime example.

The passion for general theories to explain all unexplained disease has permeated medical thought throughout history and persists today. When I was a student the era of focal sepsis was just coming to an end but patients were still being asked to sacrifice teeth, tonsils, and other of their less necessary organs in the hope of cure of some chronic ailment. This gave way to the psychosomatic era, then the diseases of adaptation, and now autoimmunity and its extensions. Holistic medicine is currently being advocated, but since it has been described as being "a new map of old territory"8 perhaps it is pushing on an open door. In all previous eras of embracing theories the refining tool of the controlled clinical trial was not available. But it is now, and while we must always be receptive to new thought there is a difference, I would submit, between an open mind and a hole in the head. We owe it to our patients to remember this.

In the early part of last century, when our horseback physician practised, most people lived and died without the help or hindrance of doctors. His meeting with his patient in the picture was obviously a casual affair. Doctors worked mainly in the cities and made their living by attending to the middle class of society. The primary function of hospitals then was largely the care, not the cure, of the poorer sick members of society. The well to do would never have dreamt of going into hospital when ill. The expectations of society in relation to the medical profession were limited, and naturally so when death from disease was all around.

The dramatic improvement in health in recent times has to some extent plateaued, so that the observed impact of new knowledge grows progressively less. Some would say that this has led to unrealistic expectations about health, and the failure of the medical profession to met these expectations has resulted in a degree of disillusion. This shines through some recent criticisms of the profession in the press and on television. Criticism from within 


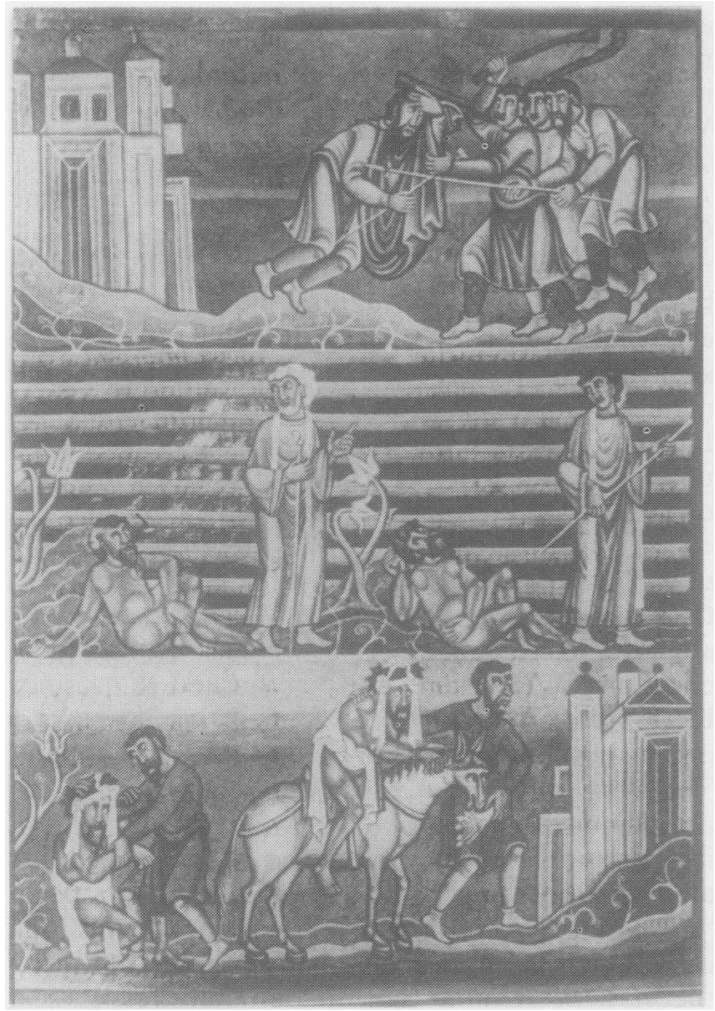

Fig 4 The Good Samaritan: eleventh century miniature, Escorial, Spain.

the profession is also not lacking. Let me give three examples.

Professor John McCormick in his thoughtful book entitled The Doctor-Father Figure or Plumber? examines the thesis that modern doctors have perhaps neglected an ethical responsibility concerned with service, an unwritten promise to society which transcends any written contract of duties and responsibilities. ${ }^{9}$. This, he feels, has led to an alteration in the relationship between society and the profession, so that doctors may be in danger of losing the special place in society which has been their privilege since organised communities began. He emphasises the fact that in the eyes of society service is the price of privilege.

Sir George Pickering in his 1964 Harveian Oration "Physician and scientist" rejoiced that he had been privileged to be both. ${ }^{6}$ But in his later years he felt that medicine had reached a crossroads and he feared that the profession had already chosen a downhill road that would reduce it from the level of a learned profession to a technological trade union.

Before he died in 1981 Walsh McDermott, a good friend of British thoracic medicine, addressed him- self to the criticism that medicine was perhaps being overinfluenced by the rapidity of technical advance and that a mechanistic, technically orientated approach was supplanting the so called caring component of medical practice. In an unfinished paper entitled "Technology's consort" 10 he emphasised the importance of the personal support function of the doctor, which he called Samaritanism from the Biblical story, depicted in one of its earliest artistic forms in an eleventh century miniature produced for Emperor Henry III (fig 4). McDermott's theme was that medicine is deeply rooted not only in science but also in the Samaritan tradition. He believed that Samaritanism must be included as a legitimate object of serious biomedical study and he pointed to our obligation to link it with technology in our every contact with the sick. In our picture Samaritanism was almost all that our horseback friend had to offer.

When we attempt a synthesis of the thoughts of McCormick, Pickering, and McDermott we are led to the conclusion that the spirit of free inquiry has to be blended with a heightened sense of humanity in the doctor who truly matches up to his obligations and promises.

Finally, when I have reflected on some of the really outstanding respiratory clinicians of the past I have been conscious not only of their allegiance to teaching, to research and to high clinical standards but also of their awareness of the social responsibility of medicine. The times we live in demand such an embracing commitment and I am confident that the British Thoracic Society will continue to ensure that the response is intelligent, rational, and relevant.

\section{References}

' Wakeford R, Roberts S. Thirty years on: examination performance and career success of the 1950-1 intake of Cambridge medical students. $\mathrm{Br}$ Med J 1983; 286: 1796-8.

${ }^{2}$ Kamien M. Radical versus traditional schools: are the graduates different? Medical Teacher 1983;5:104-6.

3 Thomson A. The consummation of William Harvey. $\mathrm{Br}$ Med J 1961;ii:1303-9.

${ }^{4}$ Turner ES. Call the doctor-a social history of medical men. London: Michael Joseph, 1958.

${ }^{5}$ Himsworth $\mathrm{H}$. Society and the advancement of natural knowledge. Br Med J 1962;ii:1557-63.

6 Pickering G. Physician and scientist. Br Med J 1964; ii:1615-9.

${ }^{7}$ Booth C. The human touch. World Medicine 1983; 14: 15 .

${ }^{8}$ Hawkins J. Time to treat the whole patient. World Medicine 1983;24:35-6.

${ }^{9}$ McCormick J. The doctor-father figure or plumber? London: Croom Helm, 1979.

${ }^{10}$ McDermott W, Rogers DE. Technology's consort. Am J Med 1983;74:353-8. 